\title{
Application of habitat suitability modelling to tracking data of marine animals as a means of analyzing their feeding habitats
}

\author{
Henrik Skov ${ }^{a, *}$, Elizabeth Humphreys ${ }^{b}$, Stefan Garthe ${ }^{c}$, Kerstin Geitner ${ }^{d}$, \\ David Grémillet ${ }^{e}$, Keith C. Hamer ${ }^{b}$, Janos Hennickef, \\ Hjalte Parner $^{g}$, Sarah Wanless ${ }^{h}$ \\ a DHI Water \& Environment, Agern Alle 5, 2970-DK Hørsholm, Denmark \\ ${ }^{b}$ Institute of Integrative and Comparative Biology, University of Leeds, Leeds LS2 9JT, United Kingdom \\ c FTZ, University of Kiel, Hafentörn 1, 25761-D Büsum, Germany \\ d Danish Fisheries Research Institute, Charlottenlund Slot, 2900-DK Charlottenlund, Denmark \\ e Centre d'Ecologie Fonctionnelle et Evolutive, CNRS, 1919 route de Mende, F-34293 Montpellier Cedex 5, France \\ ${ }^{\mathrm{f}}$ Department of Ecology and Conservation, Institute of Zoology, University of Hamburg, \\ Martin-Luther-King-Platz 3, 20146-D Hamburg, Germany \\ g Danish Fisheries Research Institute, Kavalergården, 2900-DK Charlottenlund, Denmark \\ h CEH Banchory, Hill of Brathens, Banchory, Aberdeenshire AB31 4BW, United Kingdom
}

\section{A R T I C L E I N F O}

\section{Article history:}

Received 9 September 2006

Received in revised form

1 October 2007

Accepted 2 November 2007

\section{Keywords:}

Habitat suitability model Marine animal tracking data

Presence-only models

Northern gannet Morus bassanus

\begin{abstract}
A B S T R A C T
This paper investigates the potential for using quantitative applications of statistical models of habitat suitability based on marine animal tracking data to identify key feeding areas. Presence-only models like Ecological Niche Factor Analysis (ENFA) may be applicable to resolve habitat gradients and potentially project habitat characteristics of tracked animals over large areas of ocean. We tested ENFA on tracking data of the northern gannet (Morus bassanus) obtained from the colony at Bass Rock, western North Sea in 2003. A total of 217 diving events were selected for model development. The ecological variables of the model were calibrated by using oceanographic structures with documented influences on seabird distribution, derived from satellite and bathymetric data. The model parameters were estimates of habitat marginality and specialisation computed by comparing the distribution of the gannet in the multivariate oceanographic space encompassed by the recorded logger data with the whole set of cells in the study area. Marginality was identified by differences to the global mean and specialization was identified by the ratio of species variance to global variance. A habitat suitability index was computed on the basis of the marginality factors and the first four specialisation factors by allocating values to all grid cells in the study area, which were proportional to the distance between their position and the position of the species optimum in the factorial space. Although gannets were using a large sector of the North Sea for feeding, ENFA estimated high habitat suitability scores within a relatively small coherent zone corresponding to a hydrographic frontal area, located east of the colony. The model was evaluated by using Jack-knife cross-validation and by comparison of the predicted core feeding area with results from historic field surveys. We discuss the limitations and potentials for applying habitat suitability models to tracking data in the
\end{abstract}


marine environment, and conclude that the inclusion of hydrodynamic variables seems to be the biggest constraint. Overcoming this constraint, ENFA provides a promising method for achieving improved models of the distribution of marine species with high research and conservation priority. Due to the better coverage of entire feeding ranges, the limited influence of historic factors and the lack of bias from sampling design, marine animal tracking may provide better data than at-sea surveys for habitat suitability modelling.

(c) 2007 Elsevier B.V. All rights reserved.

\section{Introduction}

Predictive geographical modelling has recently gained importance as a tool for estimating habitat suitability within a wide range of biodiversity and management studies, including studies in the marine environment (Leverette, 2004; MacLeod, 2005; Santos et al., 2006; Seoane et al., 2005). Parallel to the development of habitat suitability modelling, tracking programs for marine animals have developed rapidly at national, regional and international levels as a means to increase knowledge of animal movements and habitat use in the ocean (Block et al., 2001; Bonfil et al., 2005; Lowry et al., 1998; Schaffer et al., 2005; Tuck et al., 1999; Weimerskirch et al., 2002; Weng Q2 et al., 2005). Due to their potentially better spatio-temporal coverage of entire feeding ranges tracking data as compared to sightings and survey data may offer a less biased account of the distribution of wide-ranging species at sea. Undoubtedly, the advancement of the technology of implanted or satellite-linked data storage tags has improved the basis for precise geo-location of tagged animals. In addition, the development of better integrated systems for obtaining, analyzing and mapping animal tracking data has improved the basis for linking biological and physical data obtained from the tags with physical oceanographical and marine biological data in order to better understand the habitat requirements of marine species (Block, 2005; Coyne and Godley, 2005). Unlike direct observations or other human-inferred registrations of animals, tracking data effectively have no false positives, i.e. quality-assured observations are all both accurate and valid and hence should be applicable to predictive presence-only models like PCA, Ecological Niche Factor Analysis (ENFA, Hirzel et al., 2002), Bioclim (Farber and Kadmon, 2003), Genetic Algorithm for Rule-set Prediction (GARP, Stockwell and Peters, 1999) and Domain (Carpenter et al., 1993). However, most analyses of marine habitat characteristics based on marine tagging data rely on isopleth-mapping in GIS and descriptive statistics using overlays of satellite sea surface temperatures, water depth, ocean colour and fish distribution. There is a lack of quantitative applications of statistical models of habitat use, which is probably related to the limitations and properties of tracking information as presence-only data.

Ecological niche modelling as implemented in ENFA and GARP provides a means for modelling the dimensions of species' ecological niches, described as the quantity that governs the limits of geographic distributions of species (Grinnell, 1917; MacArthur, 1972), and offers considerably improved analytical and predictive possibilities by relating point occurrence data to geographic information about the ecological and environmental characteristics of a landscape. The ecological niche model for a species is measured in terms of marginality (the difference between the mean of the distribution of the cells representing species observations and the global cells) and specialisation (the difference between the variance of the species and the global cells). The niche model can then be projected onto a landscape to identify geographical regions that have conditions inside and outside the species' niche, producing a suitability map of a potential geographical distribution for the species. These properties may make ENFA particularly suitable for predicting habitats of marine animals from tracking data, because the distribution and habitat preferences of marine predators are typically non-random, characterised by wide (often ocean-wide) ranges contrasting to localised concentrations at the scale of less than $100 \mathrm{~km}$, often less than $50 \mathrm{~km}$ (Schneider and Duffy, 1985). ENFA has been applied successfully to presence-only data in terrestrial (Hortal et al., 2005; Zimmermann, 2004) and marine ecology (Leverette, 2004) and has also been applied successfully to terrestrial telemetry studies (Freer, 2004).

Here we apply ENFA to tracking data for northern gannets (Morus bassanus) breeding at Bass Rock, south-east Scotland in 2003 and use satellite-derived hydrographical data and bathymetric data known to influence the distribution of piscivorous seabirds as ecological variables. As the distribution and feeding habitat of the northern gannet has been intensively studied by surveys in the western part of the North Sea, the Bass Rock tracking data provided a unique opportunity to test the application of ENFA or other presence-only models with tracking data for obtaining improved estimates of the distribution and feeding habitats of marine animals.

\section{Methods}

\subsection{Study area}

In early July 2003, northern gannets were tagged on Bass Rock, a major breeding colony of the species located at the entrance to the Firth of Forth, Scotland (Fig. 1). As the feeding movements of the tagged birds extended up to $500 \mathrm{~km}$ from Bass Rock, the study area comprised the entire North Sea excluding the Skagerrak and the approaches to the English Channel. Summer conditions in the area immediately east of Bass Rock are characterized by the discharge of riverine water through the Firth of Forth, mixed Scottish coastal water running southwards along the coast, a tidal mixing front located approximately $50 \mathrm{~km}$ east of the British coast, seasonally stratified Central North Sea water east of the tidal front and relatively shallow banks located within $30-50 \mathrm{~km}$ of the colony. Analyses of satellite tracking data from Bass Rock strongly suggest that individual northern gannets show site fidelity with successive feeding trips to very similar locations (Hamer et 


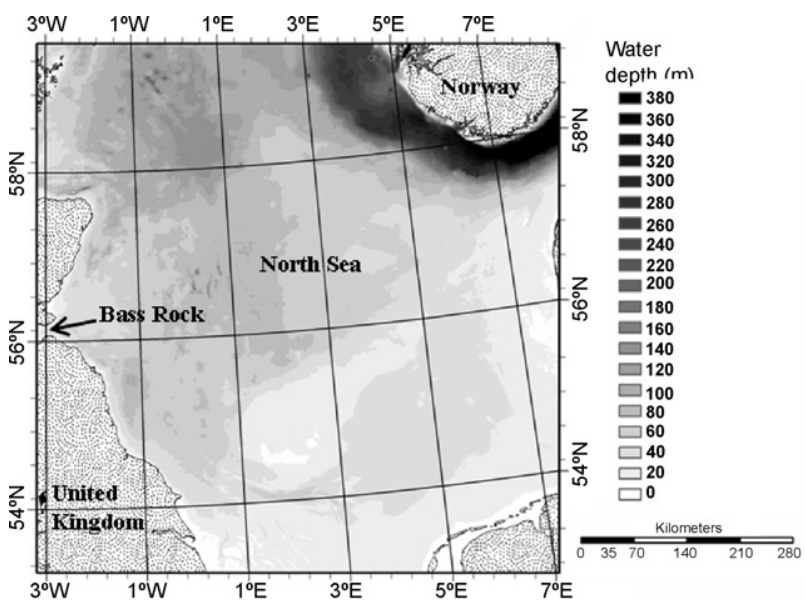

Fig. 1 - Study area with bathymetry and an indication of the gannetry at Bass Rock.

al., 2001). The northern gannet is a piscivorous species, and it feeds predominantly on sandeel (Ammodytes spp.), together with pelagic species like mackerel (Scomber scombrus) and herring (Clupea harengus) (Hamer et al., 2000).

\subsection{Tracking data}

The tracking data were collected by small GPS recorders (GPSTDlog, Earth \& Ocean Technologies, Kiel, Germany) developed during the IMPRESS project (Camphuysen, 2005) and deployed on 20 northern gannets during the chick rearing period in July and early August 2003. Compared to satellite transmitters, the GPS loggers provide greater accuracy and precision of records, and sample positions at a much higher rate, thus providing a higher spatial resolution (Hamer et al., 2007). As the sampling interval of the GPS logger was set to record positions every three minutes, the device allowed for detailed routing of movements between the breeding colony and feeding areas as well as small-scale feeding movements. In addition to position, the loggers provided data on diving behaviour via an integrated pressure sensor on a 2-s sampling interval, which together with the high frequency of positional records made it possible to separate diving events from movements more accurately. A total of 217 diving events were selected for model development, which overlapped satellite night-time images of sea surface temperature. Diving events were computed as presence values and converted to a $1 \mathrm{~km} \times 1 \mathrm{~km}$ raster file by recording the sum of the diving events in each pixel. The resolution of the diving events raster file was determined by the resolution of available satellite data (see below).

\subsection{Model variables}

Eco-geographical variables consisted of geographic, topographic and pelagic variables (Table 1). The geographic variables were comprised of Euclidean distances to colony and land, while topographic and pelagic variables were derived from a digital depth model and NOAA AVHRR SST data (the preparation of these data is described below). The ecogeographical variables were developed and calibrated using
Table 1 - List of eco-geographical variables

\begin{tabular}{ll}
\hline Parameter & \multicolumn{1}{c}{ Unit } \\
\hline Distance to Bass Rock Colony & $\mathrm{km}$ \\
Distance to land & $\mathrm{km}$ \\
Bathymetry of sea floor & $\mathrm{m}$ \\
Slope of sea floor & $\%$ \\
Eastern aspect of sea floor & Range -1 to 1 \\
Northern aspect of sea floor & Range -1 to 1 \\
North Sea water mass & Frequency range 0-1 \\
Scottish coastal water mass & Frequency range 0-1 \\
Tidal shelf front & Frequency range 0-1 \\
Forth River plume front & Frequency range 0-1 \\
\hline
\end{tabular}

published data on environmental gradients in the distribution of piscivorous seabirds, which highlight the importance of shelf fronts as a key habitat (Begg and Reid, 1997; Bourne, 1981; Decker and Hunt, 1996; Hémery et al., 1986; Kinder et al., 1983; Leopold, 1987; Pingree et al., 1974; Schneider, 1982). GIS grids were created in UTM $30 \mathrm{~N}$ (wgs 84 ) with a $1 \mathrm{~km}$ resolution covering the region defined by the coordinates $54^{\circ} \mathrm{N}-59^{\circ} \mathrm{N}$, $3^{\circ} \mathrm{W}-2^{\circ} \mathrm{E}$.

\subsubsection{Topographic variables}

2.3.1.1. Water depth. Water depth was derived using a digital depth model in $1 \mathrm{~km} \times 1 \mathrm{~km}$ resolution based on linear, ordinary kriging with no constraints on the search ellipse using the North Sea bathymetry of DHI Water \& Environment and data collected in relation to the IMPRESS project.

2.3.1.2. Bottom slope. Based on the depth grid, a grid with the slope (in \%) of the sea floor of the eastern part of the North Sea was estimated by using the formula from Monmonier (1982).

2.3.1.3. Eastern and northern aspects. The eastern and northern aspects were calculated by taking the sine and cosine, respectively, of the direction of the maximum slope values.

\subsubsection{Pelagic variables}

Pelagic variables were discerned from the night-time NOAA AVHRR SST images, which were cloud-free for the area. A total of 17 cloud-free SST images overlapped the 217 diving events by at least $3 \mathrm{~h}$, and were retained for analysis. Raw NOAA AVHRR satellite data (NOAA satellites 12, 14 and 16) were obtained from the Dundee Satellite Receiving Station. To avoid skin-effects on the classification of surface structures only night-time images were used. Calibration followed algorithms described by NOAA/NESDIS in the NOAA KLM User's Guide www2.ncdc.noaa.gov/docs $/ \mathrm{klm} /$. Sea surface temperatures were estimated using algorithms available on the NOAA/NESDIS web server http://noaasis.noaa. gov/NOAASIS/pubs/SST. Rectified and calibrated image scenes were examined in order to exclude pixels not qualifying to be used in the calculation of the sea surface temperature such as pixels over land, pixels with large satellite zenith angles $\left(>53^{\circ}\right)$ and pixels contaminated containing clouds. The cloud detection algorithms IR Gross Cloud Test, IR Uniformity Cloud Test and IR Difference Cloud Test developed by the Commonwealth Bureau of Meteorology were applied to exclude cloud contaminated pixels. 
Classification of water masses and fronts was made by a combination of gradient analyses and surface temperature characteristics. Water masses were classified using known temperature ranges applying raster filter and re-classification procedures. Frontal variables have generally been recognised from satellite images by boundaries between water masses (Fiedler and Bernard, 1987; Haney, 1989; Johannessen et al., 1989). In general, surface fronts are defined as regions of high horizontal gradients (Mann and Lazier, 1991). Technically, surface fronts may be determined from SST images using edge detection algorithms or slope analysis. However, these routines were found to create unsatisfactory classifications of frontal variables due to the relatively large amount of noise in the SST images. Better results in terms of contiguous frontal patterns were generated using a gradient analysis followed by re-classification procedures to define frontal pixels on the basis of threshold slope values. Following re-classification clusters of frontal pixels were combined into contiguous structures using group and re-classification procedures.

The following pelagic variables were classified: North Sea water, Scottish coastal water, tidal shelf front and Forth River plume front. The variables were classified for each image-GPS logger data pair and the frequency of each variable class was then calculated for the entire data set. The calculation of average frequency values took account of cloud cover by masking clouded areas as 'missing values'. Frequencies of occurrence of water masses and fronts were coded using an index from 0 to 1 with 1 being equivalent of a frequency of $100 \%$.

\subsection{Model parameters}

Selected gannet diving event records were collated into a GIS layer as the total number of presences per pixel. Normalisation of the eco-geographical GIS layers and modelling of covariance matrix, Ecological Niche Factor Analysis (ENFA) and habitat suitability scores were carried out using a combination of ArcGIS version 9.0, Biomapper version 3.0 and Idrisi version 3.2. All topographic and hydrographical variables were normalized through the 'Box-Cox' algorithm (Sokal and Rohlf, 1981), although ENFA is not considered very sensitive to the frequency distribution of variables (Hirzel et al., 2002).

\subsubsection{Analysis of habitat marginality and specialisation}

Suitability functions were computed by comparing the distribution of the gannet in the multivariate oceanographic space encompassed by the recorded logger data with the multivariate oceanographic space of the whole set of cells in the study area (Hirzel, 2001). On the basis of differences in the gannet and global 'space' with respect to their mean and variances, marginality of gannet records was identified by differences to the global mean and specialisation by a lower species variance than global variance. Thus, for large geographical areas like the part of the North Sea studied here, ENFA approaches Hutchinson's concept of ecological niche, defined as a hypervolume in the multi-dimensional space of ecological variables within which a species can maintain a viable population (Hutchinson, 1957).

Marginality $(M)$ was calculated as the absolute difference between the global mean $\left(M_{\mathrm{g}}\right)$ and the mean of the gannet logger data $\left(M_{S}\right)$ divided by 1.96 standard deviations of the global distribution $(g)$

$M=\frac{\left|M_{g}-M_{s}\right|}{1.96 \sigma_{g}}$,

while specialisation (S) was defined as the ratio of the standard deviation of the global distribution to that of the species distribution:

$S=\frac{\sigma_{g}}{\sigma_{\mathrm{S}}}$

To take account of multi-colinearity and interactions among eco-geographical factors, indices of marginality and specialisation were estimated by factor analysis; the first component being the marginality factor passing through the centroid of all gannet observations and the centroid of all background cells in the study area, and the index of marginality measuring the orthogonal distance between the two centroids. Several specialisation factors were successively extracted from the $n-1$ residual dimensions, ensuring their orthogonality to the marginality factor while maximising the ratio between the residual variance of the background data and the variances of the gannet occurrences. A high specialisation indicates restricted habitat usage compared to the range of conditions measured in the studied part of the North Sea. Obviously, ENFA is highly sensitive to the location and size of study area, and this was one of the reasons for choosing a large study area covering most of the North Sea.

\subsubsection{Habitat suitability modelling}

A habitat suitability index was computed on the basis of the marginality factors and the first four specialisation factors, as a high proportion of the total variance was explained by the first few factors, by comparison to a broken-stick distribution. The habitat suitability algorithm allocated values to all grid cells in the study area, which were proportional to the distance between their position and the position of the species optimum in factorial space. We used the geometric mean algorithm for habitat suitability computation, as it allows for an improved estimation of habitat suitability in situations with non-unimodal distributions (Hirzel and Arlettaz, 2003). In this algorithm habitat suitability is calculated as the geometric mean $\left(\mu_{\mathrm{G}}\right)$ of the weighted Euclidean distances $(\delta)$ from any point $P$ of the environmental space to all species points $\left(O_{i}\right)$ :

$\mu_{G}(P)=\sqrt[N]{\pi \frac{N}{i=1} \delta\left(P, O_{i}\right)}$.

The mean distances range from 0 to infinity, and envelopes are delineated encompassing hypervolumes with values below a certain threshold. The habitat suitability index ranging from 0 to 100 is calculated based on the number of observation points within each envelope.

\subsubsection{Evaluation}

As no independent data were available, the predictive accuracy of the suitability maps was evaluated by a Jack-knife cross-validation procedure following the method described by Boyce et al. (2002), which produces a confidence interval around the predicted accuracy of the habitat model. The gannet GPS logger locations were randomly partitioned into 100 mutually exclusive but identically sized sets, 99 partitions 
were used to compute a habitat suitability model and one partition was used for validation. The process was repeated 100 times, each time omitting a different partition.

The distribution of northern gannets in the modelled part of the North Sea has been studied during ship-based surveys carried out over the past 17 years (European Seabirds at Sea Database). To assess the application of ENFA we compared the modelled area of high habitat suitability with the mean distribution discerned from the cumulative historic survey database for the summer period.

\section{Results}

Application of ENFA provided an overall marginality of $m=1.99$ and an overall specialization value of $S=2.61$, showing that Bass Rock gannets' feeding habitat in 2003 differed markedly from the mean conditions in the studied part of the North Sea. The five factors retained accounted for $95 \%$ of the sum of the eigenvalues (that is $100 \%$ of the marginalization and $95 \%$ of the specialization, Table 2). Marginality accounted for $17 \%$ of the total specialization, while the first two specialization factors accounted for $64 \%$ of the total specialization, indicating that gannets are moderately restricted in the range of conditions they utilize in the study area. It is also evident from the plot of feeding events in Fig. 2 that gannets use a wide range of areas in the North Sea for feeding.

Marginality coefficients showed that gannets were linked to the dynamic habitat variables and the distance to Bass Rock, whereas the topographic variables proved of little or no importance to gannet habitat (Table 2). Gannet feeding was clearly linked to both of the two coastal water masses and the front between them as well as the tidal shelf front towards the stratified North Sea water mass which was of limited importance (Fig. 3). The marginality and specialization scores lead to habitat suitability scores ranging from 0 to 100 , the upper 33 reflecting suitable habitat (Fig. 4). The pixels indicating high habitat suitability all lie within a coherent zone corresponding to the area of the Forth River front and the Scottish coastal water in proximity to Bass Rock and the entire area of the tidal shelf front, extending along the east coast of Scotland.

A profile of the variation of the modelled habitat suitability scores from the Forth River across the colony at Bass Rock

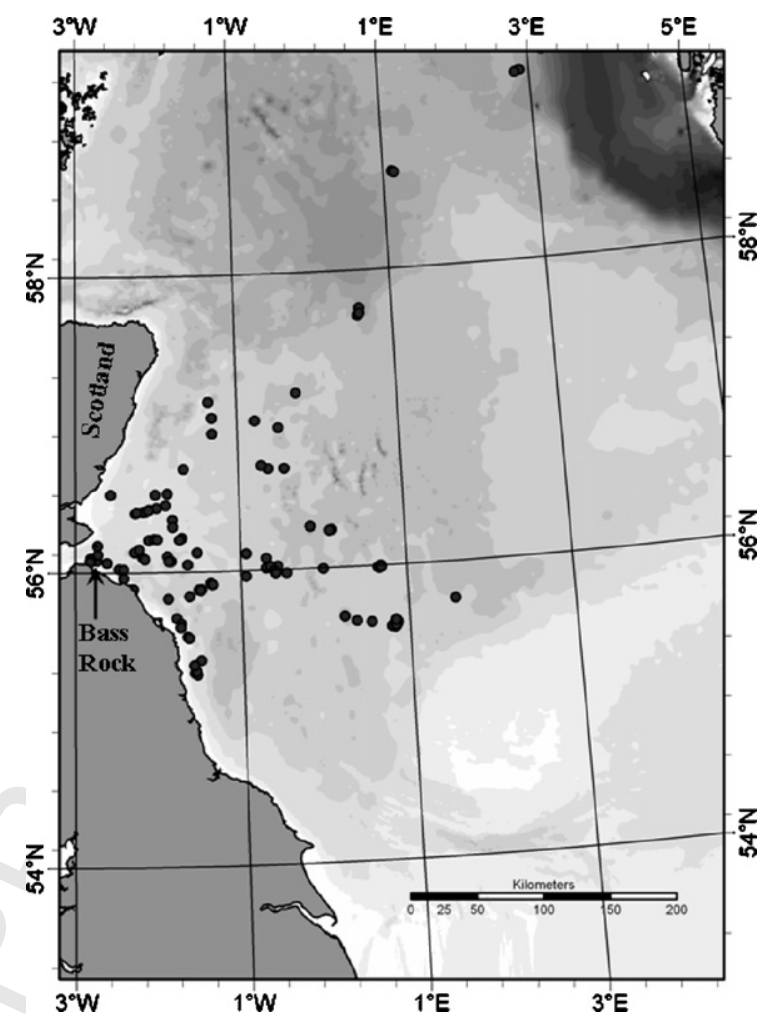

Fig. 2 - Plot of available geo-locations of diving events for gannets (Morus bassanus) in July 2003 overlapping NOAA AVHHR images.

and into the North Sea shows that the zone of suitable habitat lies approximately $25 \mathrm{~km}$ east of the colony and extends some $50 \mathrm{~km}$ eastwards into the North Sea (Fig. 5). The profile also shows that the suitability drops sharply when approaching Bass Rock to the west of the "suitable habitat" zone and the North Sea water to the east. The small drop in the centre of the high-suitability zone approximately $50 \mathrm{~km}$ from Bass Rock is probably a bias introduced by the heterogeneity of the NOAA satellite data created by extensive cloud cover on most days.

The results of the Jack-knife cross-validation procedure (Boyce et al., 2002) revealed a narrow confidence interval

Table 2 - Amount of specialisation explained by the first five factors

\begin{tabular}{|c|c|c|c|c|c|}
\hline Eco-geographical variable & Marginality (17\%) & Spec. $1(39 \%)$ & Spec. $2(25 \%)$ & Spec. $3(11 \%)$ & Spec. $4(3 \%)$ \\
\hline Scottish coastal water & 0.499 & 0.029 & 0.185 & -0.144 & 0.472 \\
\hline Distance Bass Rock & -0.492 & 0.104 & -0.221 & 0.187 & 0.379 \\
\hline Forth river front & 0.432 & -0.012 & 0.040 & -0.037 & 0.060 \\
\hline Tidal shelf front & 0.387 & -0.032 & 0.064 & -0.011 & 0.084 \\
\hline North sea water & -0.280 & -0.002 & 0.058 & 0.068 & 0.701 \\
\hline Distance land & -0.277 & -0.475 & 0.741 & -0.525 & -0.316 \\
\hline Bathymetry & 0.091 & -0.858 & -0.229 & 0.571 & 0.120 \\
\hline Northern aspect & -0.032 & 0.026 & -0.002 & 0.003 & -0.017 \\
\hline Eastern aspect & 0.087 & 0.000 & -0.051 & 0.012 & -0.118 \\
\hline Slope of sea floor & 0.008 & 0.160 & 0.551 & 0.580 & -0.056 \\
\hline
\end{tabular}

Eco-geographical variables are sorted by decreasing absolute values of coefficients on the marginality factor. The amount of variation accounted for is given in parentheses. 


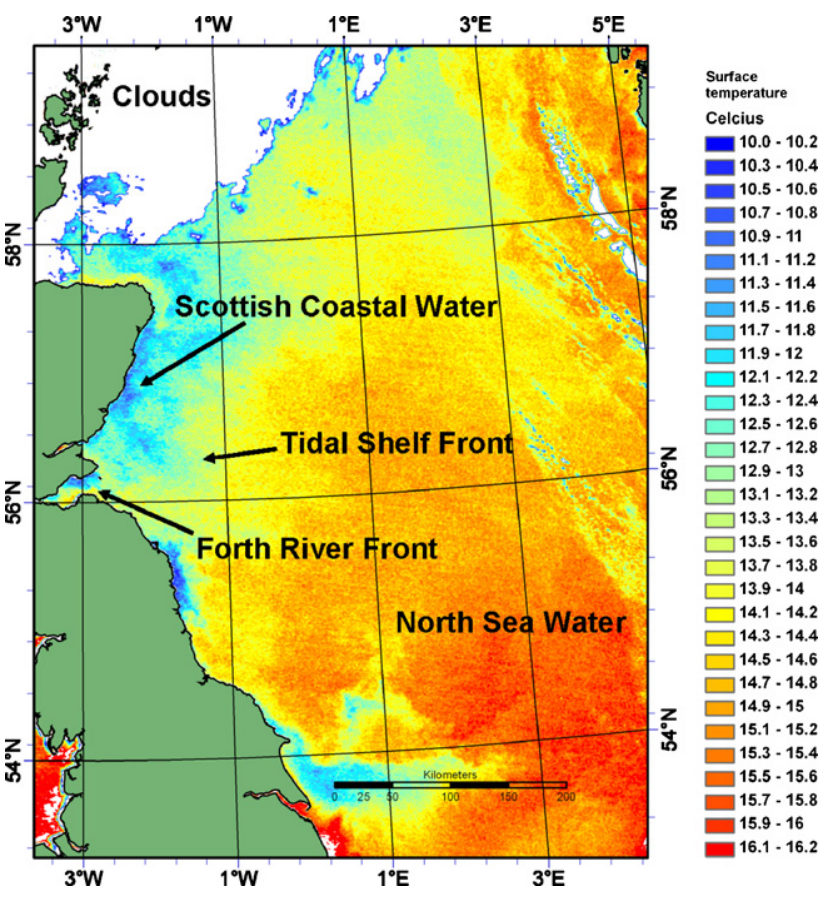

Fig. 3 - NOAA AVHHR SST image taken at 13 July 20030230 with indications of typical positions for the main water masses and surface frontal features.

around the predicted habitat suitability profiles, indicating a satisfactory predictive capacity of the model (Fig. 5). The interpretation of the suitability scores in relation to the regional oceanography is consistent with the experience of field ornithologists, and the modelled zone of high habitat

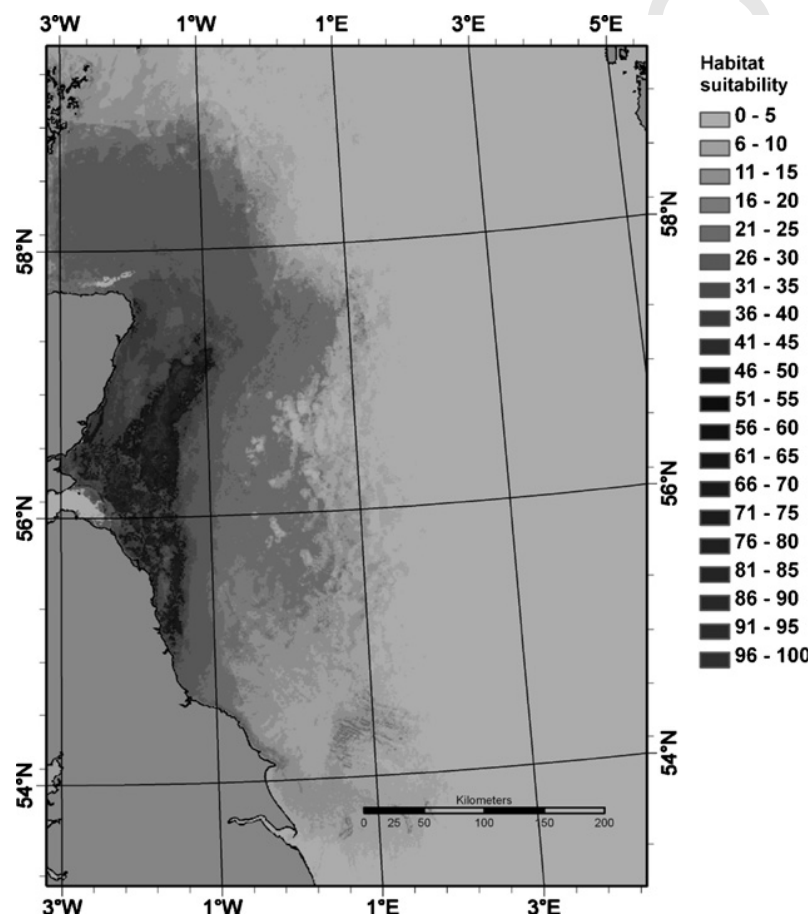

Fig. 4 - Habitat suitability scores computed by ENFA for diving northern gannets in July 2003.

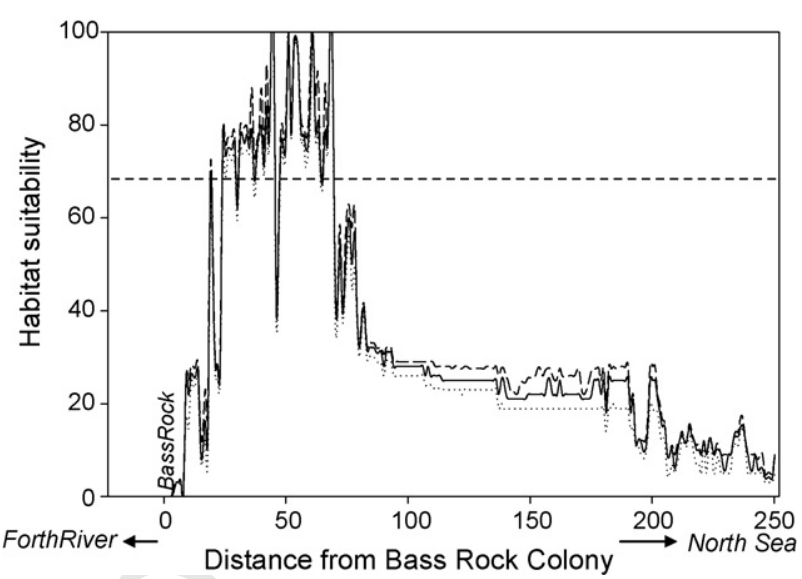

Fig. 5 - Variation of modelled habitat suitability scores (mean and 95\% confidence interval) with distance ( $\mathrm{km}$ ) along an east-running line from the Scottish coast across the colony at Bass Rock and $250 \mathrm{~km}$ into the North Sea. Suitable habitat scores are indicated by the value of 67 (stipled line).

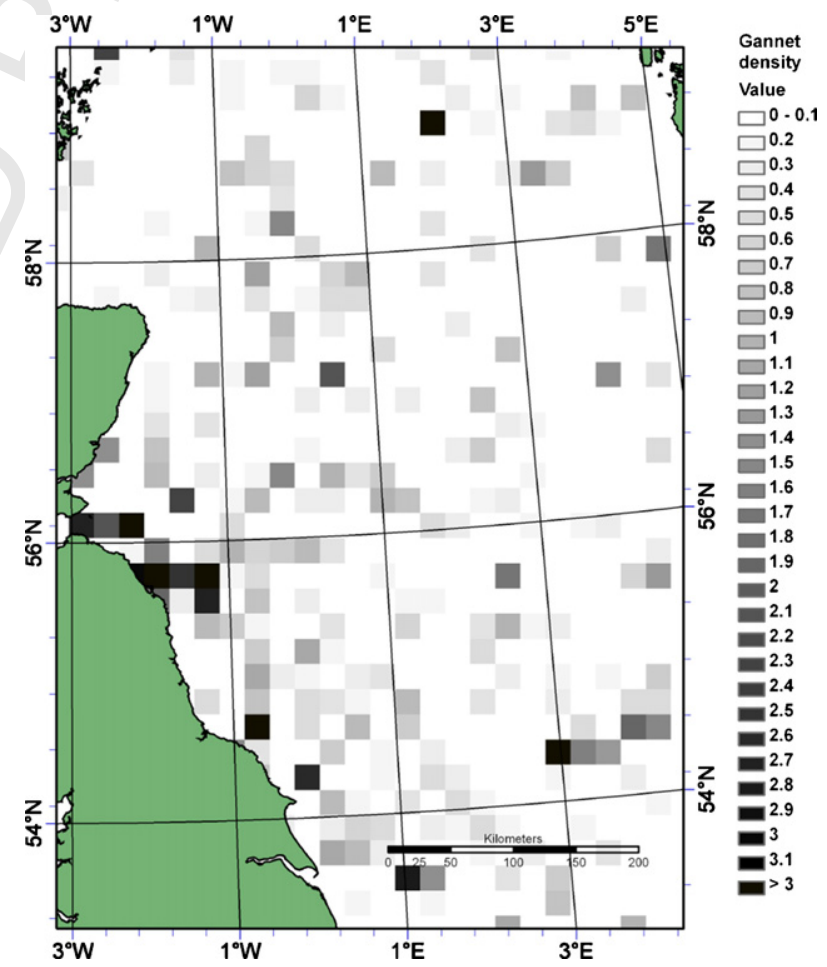

Fig. 6 - Average densities of gannets (no. of birds per $\mathrm{km}^{2}$ ) observed by ship-based surveys off the Scottish coast during the summer period (May-August) between 1987 and 2004 (based on data from the European Seabirds at Sea Database). Densities are indicated at a spatial resolution of $20 \mathrm{~km}$.

suitability to a large degree overlapped with the area characterized by high densities of feeding gannets from historic survey data (Camphuysen, 2005, Figs. 4 and 6). Compared to the survey data, the modelled area of high habitat suitability 

area.

\section{Discussion and conclusion}

The ENFA model provided a confident delineation of a coherent, yet complex pattern of potential feeding habitat of gannets from Bass Rock in 2003 based on the GPS logger data. Although gannet feeding was recorded by the tagging data over a wide range of the North Sea, the modelled coherent zone of high habitat suitability values clearly fitted the location of most fixes at the Forth River front and the Scottish coastal water in proximity to Bass Rock and the entire area of the tidal shelf front extending along the east of Scotland. The combination of a wide range of conditions and a tendency to concentrate in areas of specific oceanographic variables (i.e. the tidal shelf front) may be typical for a piscivorous seabird. This characteristic was further underlined by the combination of a low marginality factor and a relatively low tolerance value. A wide range of seabird species have been recorded in elevated densities at tidal mixing fronts like this one. In the northern hemisphere these variables seem to be of particular importance to sub-surface and pursuit diving species like manx shearwater (Puffinus puffinus), common guillemot (Uria aalge) and razorbill Alca torda specialising on schooling fish (Begg and Reid, 1997; Decker and Hunt, 1996; Kinder et al., 1983; Leopold, 1987; Schneider, 1982).

These results indicate that ecological niche analyses with tracking data using marginality/tolerance weighting have the capacity to provide satisfactory and precise predictions of distribution patterns and feeding habitats of animals in the ocean. Due to the better coverage of entire feeding ranges, the limited influence from historic factors (Leathwick, 1998) and lack of bias from sampling design (Guisan and Zimmermann, 2000) tracking data may provide better data than surveys for habitat suitability modelling. Provided important habitat variables are known and available for a large region in a raster GIS format ENFA may be used to extract suitability gradients for marine species to much the same extent as for terrestrial species.

Computation of reliable specialisation and marginality factors in ENFA rely heavily on a representative sample of observations (tracking data) in relation to the distribution of the species. Accordingly, samples from populations located at the extreme of the species' range may not reflect the typical diversity of habitat types and hence may provide habitat gradients with limited scope for extrapolation. Even more importantly, samples from a small part of the actual foraging range associated with a breeding colony may bias the output from ENFA. The part of the North Sea which we included in the model corresponds more or less to the entire feeding range of gannets from this colony (Hamer et al., 2001), and thus the predicted habitat suitability is likely to represent an un-biased estimate of the area-use by gannets breeding at Bass Rock in 2003.

Many species of marine animals used in tagging studies are patchily distributed with feeding aggregations occurring over spatial scales less than $100 \mathrm{~km}$. Elaborate analyses of the scale-dependent intensity of aggregation of seabird species groups including Procellariiformes, Laridae and Alcidae have documented maximum values at the scale of $10-50 \mathrm{~km}$ (Briggs et al., 1987; Schneider and Duffy, 1985). Gradients at smaller scales generally reflect species-specific foraging and flocking dynamics (Schneider, 1990). As maximum foraging ranges may be very large and the animals have to travel large distances between feeding aggregations, the majority of tagging data may reflect animals moving between feeding areas. As a consequence, post-processing of tagging data to retrieve data on feeding activities is an important pre-requisite for modelling of habitat suitability on the basis of comparisons of global and species means and standard variations of distributions of ecovariables in the multi-dimensional space. As in this case study, the application of high-frequency loggers allowed for identification of potentially feeding birds on the basis of distances between individual fixes and diving depths.

One of the primary requirements for producing reliable habitat suitability modelling is the availability of input data on eco-variables with high accuracy and resolution (Guisan and Zimmermann, 2000). In the marine environment, most habitat modelling has been carried out using topographical and seascape characteristics rather than hydrodynamic variables as ecovariables (Leverette, 2004; MacLeod, 2005). Our results indicate that the inclusion of hydrodynamic variables potentially may increase the predictive power of ENFA models for marine animals. Most of the topographic variables had only a minor influence on the marginality factor. The use of SST data allowed for the classification of surface hydrographical variables and estimation of their frequencies at different locations in the study area. However, hydrodynamic modelling will provide an improved basis for resolving potentially important dynamic variables. Pycnocline depth and other structures of the water column have been documented as important feeding habitats to diving marine birds (Briggs et al., 1988; Haney, 1991; Hunt and Harrison, 1990; Hunt et al., 1990; Skov and Durinck, 2000), hence characteristics of surface waters may be insufficient to generate habitat characteristics for diving predators. In addition, modelling of frontal characteristics is now possible at even very small scales (Langenberg, 1997), and often provide the only means to resolve the inherent shortterm variability of hydrographic structures like fronts.

Other, more process-related variables such as prey concentrations, are often mentioned as potential predictors of marine animal distributions (Williams et al., 2006). However, the response pattern of seabirds to the distribution of prey indicates that seabirds often react to prey abundance at geographical scales considerably larger than that of a single prey patch, and the adaptations to predictable oceanographic structures shown for several species indicate that optimisation of prey detection in seabirds principally occurs within the coarse-scale boundaries of the oceanographic structures (Fauchald et al., 1999). This is corroborated by the observations of stronger seabird-prey associations in frontal regions (Decker and Hunt, 1996).

Based on the above it seems that the biggest restrictions regarding the potential application of ENFA models to marine tagging data are due to the nature of the sampled data, for example in terms of size, behavioural characteristics and coverage in relation to the main distribution and foraging ranges of the species in question. However, these 
restrictions are related to the amount of available resources rather than constraints of ENFA models. A major constraint, however, seems to be the availability of concurrent 3D hydrodynamic model data. Even if these constraints are overcome, it is important to be cautious regarding the use of ENFA for more than descriptive purposes. The estimated habitat suitability and the weighting of the different eco-variables on the main factors in ENFA do not provide any information to support quantitative judgements of causal relationships between the species' distribution and individual parameters. Yet, the potential of ENFA as a means to project habitat gradients to vast areas of ocean using logger data is great and promises to be able to greatly assist activities for mapping and modelling marine biodiversity, e.g. in relation to the delineation of marine protected areas. In fact, the outline of the core habitat on the basis of an ENFA model based on 1 year of tagging data has provided a clearer overview of the contiguous zone used by gannets from Bass Rock as compared to historic survey data (Camphuysen, 2005, Fig. 6). ENFA's prime potential is the use of tagging data by allowing extrapolation of data from regional to basin scale to allow for the identification of priority areas for further research and conservation. Similarly, ENFA could also be used with other presence-only datasets, such as records in the international biodiversity databases and records of catches of particular species as a means for predictive modelling.

\section{Acknowledgements}

The analyses formed part of the IMPRESS (Interactions between the Marine environment, PREdators, and prey: implications for Sustainable Sandeel fisheries) project (EU contract Q5RS-2000-30864) focusing on assessments of sustainable sandeel (Ammodytidae) fisheries in the Firth of Forth, United Kingdom. We thank Sir Hew Hamilton-Dalrymple for access to the Bass Rock, and Bryan Nelson and the Marr Family for logistical support. Gerrit Peters provided useful comments on an earlier version of the manuscript.

\section{RE F E R E N C E S}

Begg, G.S., Reid, J.B., 1997. Spatial variation in seabird density at a shallow sea tidal mixing front in the Irish Sea. ICES J. Mar. Sci. 54, 552-565.

Block, B.A., Dewar, H., Blackwell, S.B., Williams, T.D., Prince, E.D., Farwell, C.J., Boustany, A., Teo, S.L.H., Seitz, A., Walli, A., Fudge, D., 2001. Migratory movements, depth preferences, and thermal biology of Atlantic Bluefin Tuna. Science 17293 , 1310-1314.

Block, B.A., 2005. Physiological ecology in the 21st century: advancements in biologging science. Integr. Comp. Biol. 45, 305-320.

Bonfil, R., Meyer, M., Scholl, M.C., Johnson, R., O’Brien, S., Oosthuizen, H., Swanson, S., Kotze, D., Paterson, M., 2005. Transoceanic migration, spatial dynamics, and population linkages of white sharks. Science 310, 100-103.

Bourne, W.R.P., 1981. Some factors underlying the distribution of seabirds. In: Cooper, J. (Ed.), Proceedings of the Symposium on Birds of the Sea and Shore. African Seabird Group, Cape Town, South Africa.
Boyce, M.S., Vernier, P.R., Nielson, S.E., Schmiegelow, F.K.A., 2002. Evaluating resource selection functions. Ecol. Model. 157, 281-300.

Briggs, K.T., Ainley, D.G., Spear, L.B., Adams, P.B., Smith, S.E., 1988. Distribution and diet of Cassin's auklet and common murre in relation to central California upwellings. In: Oulett, H. (Ed.), Proceedings of the 19th International Ornithological Congress, Ottawa, 1986. University of Ottawa Press, Ottawa, pp. 982-990.

Briggs, K.T., Tyler, W.B., Lewis, D.B., Carlson, D.R., 1987. Bird communities at sea off California: 1975-1983. Avian Biol. 11, $1-74$

Camphuysen, C.J., 2005. Understanding marine food webb processes: an ecosystem approach to sustainable sandeel fisheries in the North Sea. Final Report QRRS 2000-30864; IMPRESS: Interactions between the Marine Environment, Predators and prey: implications for Sustainable Sandeel fisheries.

Carpenter, G., Gillison, A.N., Winter, J., 1993. DOMAIN: a flexible modeling procedure for mapping potential distributions of plants, animals. Biodiv. Conserv. 2, 667-680.

Coyne, M.S., Godley, B.J., 2005. Satellite Tracking and Analysis Tool (STAT): an integrated system for archiving, analyzing and mapping animal tracking data. Mar. Ecol. Prog. Ser. 301, $1-7$.

Decker, M.B., Hunt Jr., G.L., 1996. Foraging by murres (Uria spp.) at tidal fronts surrounding the Pribilof Islands, Alaska, USA. Mar. Ecol. Prog. Ser. 139, 1-10.

Farber, O., Kadmon, R., 2003. Assessment of alternative approaches for bioclimatic modeling with special emphasis on the M-distance. Ecol. Model. 160, 115-130.

Fauchald, B., Erikstad, K.E., Skarsfjord, H., 1999. Scale-dependent predator-prey interactions: the hierarchical spatial distribution of seabirds and prey. Ecology 81 (3), 773-783.

Fiedler, P.C., Bernard, H.J., 1987. Tuna aggregation and feeding near fronts observed in satellite imagery. Cont. Shelf Res. 7, 871-881.

Freer, R.A., 2004. The Spatial Ecology of the Güiña (Oncifelis guigna) in Southern Chile. University of Durham, Durham, 219 pp.

Grinnell, J., 1917. Field tests of theories concerning distributional control. Am. Nat. 51, 115-128.

Guisan, A., Zimmermann, N.E., 2000. Predictive habitat distribution models in ecology. Ecol. Model. 135, 147-186.

Hamer, K.C., Humphreys, E.M., Garthe, S., Hennicke, J., Peters, G., Grémillet, D., Phillips, R.A., Harris, M.P., Wanless, S., 2007. Annual variation in diets, feeding locations and foraging behaviour of gannets in the North Sea: flexibility, consistency and constraint. Mar. Ecol. Prog. Ser. 338, 295-305.

Hamer, K.C., Phillips, R.A., Wanless, S., Harris, M., Wood, A.G., 2000. Foraging ranges, diets and feeding locations of gannets in the North Sea: evidence from satellite telemetry. Mar. Ecol. Prog. Ser. 200, 257-264.

Hamer, K.C., Phillips, R.A., Hill, J.K., Wanless, S., Wood, A.G., 2001 Contrasting foraging strategies of gannets Morus bassanus at two North Atlantic colonies: foraging trip duration and foraging area fidelity. Mar. Ecol. Prog. Ser. 224, 283-290.

Haney, J.C., 1989. Remote characterization of Marine Bird Habitats with Satellite Imagery. Colon. Waterbirds 12 (1), 67-77.

Haney, J.C., 1991. Influence of pycnocline topography and water-column structure on marine distributions of alcids (Aves: Alcidae) in Anadyr Strait, Northern Bering Sea, Alaska. Mar. Biol. 110, 419-435.

Hémery, G., Pasquet, E., Yesou, P., 1986. Data banks and population monitoring in France. In: Medmarvis, Monbailliu, X. (Eds.), Mediterranean Marine Avifauna. Population Studies and Conservation. Springer-Verlag, Berlin, pp. 163-177.

Hirzel, A.H., Arlettaz, R., 2003. Modelling habitat suitability for complex species distributions by the environmental-distance geometric mean. Environ. Manage. 32, 614-623. 
Hirzel, A.H., Hausser, J., Chessel, D., Perrin, N., 2002. Ecological-niche factor analysis: how to compute habitat-suitability maps without absence data? Ecology 83, 2027-2036.

Hirzel, A.H., 2001. When GIS come to life. Linking landscape- and population ecology for large population management modelling: the case of Ibex (Capra ibex) in Switzerland. Ph.D. Thesis. Institute of Ecology, Laboratory for Conservation Biology, University of Lausanne, $114 \mathrm{pp}$.

Hortal, J., Borges, P.A.V., Dinis, F., Jiménez-Valverde, A., Chefaoui, R.M., Lobo, J.M., Jarroca, S., Azevedo, E.B.d., Rodrigues, C., Madruga, J., Pinheiro, J., Gabriel, R., Rodrigues, F.C., Pereira, A.R., 2005. Using ATLANTIS-TIERRA 2.0 and GIS environmental information to predict the spatial distribution and habitat suitability of endemic species. In: Borges, P.A.V., Cunha, R., Gabriel, R., Martins, A.F., Silva, L., Vieira, V. (Eds.), A List of the Terrestrial Fauna (Mollusca and Arthropoda) and Flora (Bryophyta, Pteridophyta and Spermatophyta) from the Azores. Direcção Regional de Ambiente and Universidade dos Açores, Horta, Angra do Heroísmo and Ponta Delgada, pp. 69-113.

Hunt Jr., G.L., Harrison, N.M., Cooney, R.T., 1990. The influence of hydrographic structure and prey abundance on the foraging of least auklets. Avian Biol. 14, 7-22.

Hunt Jr., G.L., Harrison, N.M., 1990. Foraging habitat and prey taken by least auklets at King Island, Alaska. Mar. Ecol. Prog. Ser. 65, 141-150.

Hutchinson, G.E., 1957. Concluding remarks. In: Cold Spring Harbour Symposium on Quantitative Biology, vol. 22, pp. 415-427.

Johannessen, J.A., Johannessen, O.L., Haugan, P.M., 1989. Remote sensing and model simulation studies of the Norwegian coastal current during the algal bloom in May 1988. Int. J. Remote Sensing 10 (12), 1893-1906.

Kinder, T.H., Hunt Jr., G.L., Schneider, D., Schumacher, J.D., 1983. Correlations between seabirds and oceanic fronts around the Pribilof Islands, Alaska. Est. Coast. Shelf Sci. 16, 309-319.

Langenberg, H., 1997. Interaction of wind and density driven currents in North Sea ROFIs-a model study. J. Mar. Syst. 12, 157-170.

Leathwick, J.R., 1998. Are New-Zealand's Nothofagus species in equilibrium with their environment? J. Veg. Sci. 9, 719-732.

Leopold, M.F., 1987. Seabird concentrations at a tidally induced front in the southern North Sea. Netherlands Institute for Sea Research Internal Reports 1987-2002 (in Dutch with an English summary).

Leverette, T.L., 2004. Predicting suitable habitat for deep water corals in the Pacific and Atlantic Continental Margins of North America. M.Sc. Thesis. Department of Oceanography, Dalhousie University, 81 pp.

Lowry, L.F., Frost, K.J., Davis, R., DeMaster, D.P., Suydam, R.S., 1998. Movements and behavior of satellite-tagged spotted seals (Phoca largha) in the Bering and Chukchi Seas. Polar Biol. 19, 221-230.

MacArthur, R., 1972. Geographical Ecology. Princeton University Press, Princeton, NJ.
MacLeod, C.D., 2005. Niche partitioning, distribution and competition in North Atlantic beaked whales. Ph.D. Thesis. University of Aberdeen, Aberdeen, UK, 260 pp.

Mann, K.H., Lazier, J.R.N., 1991. Dynamics of Marine Ecosystems. Blackwell Scientific Publications, Boston, 341 pp.

Monmonier, M., 1982. Computer-assisted Cartography: Principles and Prospects. Prentice-Hall, Inc., Englewood Cliffs, NJ, 80 pp.

Pingree, R.D., Forster, G.R., Harrison, G.K., 1974. Turbulent convergent tidal fronts. J. Mar. Biol. Assoc. U.K. 54, 469-479.

Santos, X., Brito, J.C., Sillero, N., Pleguezuelos, J.M., Llorente, G.A., Fahd, S., Parellada, X., 2006. Inferring habitat-suitability areas with ecological modelling techniques and GIS: a contribution to assess the conservation status of Vipera latastei. Biol. Conserv. 130, 416-425.

Schaffer, S.A., Tremblay, Y., Awkerman, J.A., Henry, R.W., Teo, S.L.H., Anderson, D.A., Croll, D.A., Block, B.A., Costa, D.P., 2005. Comparison of light- and SST-based geolocation with satellite telemetry in free-ranging albatrosses. Mar. Biol. 147, 833-843.

Schneider, D.C., Duffy, D.C., 1985. Scale-dependent variability in seabird abundance. Mar. Ecol. Prog. Ser. 25, 211-218.

Schneider, D.C., 1982. Fronts and seabird aggregations in the southeastern Bering Sea. Mar. Ecol. Prog. Ser. 10, 101-103.

Schneider, D.C., 1990. Seabirds and fronts-a brief overview. Polar Res. 8, 7-22.

Seoane, J., Carrascal, L.M., Alonso, C.L., Palomino, D., 2005 Species-specific traits associated to prediction errors in bird habitat suitability modelling. Ecol. Model. 185, 299-308.

Skov, H., Durinck, J., 2000. Seabird distribution in relation to hydrography in the Skagerrak. Cont. Shelf Res. 20, 169-187.

Sokal, R.R., Rohlf, F.J., 1981. Biometry. The Principles and Practice of Statistics in Biological Research. W.H. Freeman and Company, San Francisco, 857 pp.

Stockwell, D.R.B., Peters, D.P., 1999. The GARP modeling system: problems and solutions to automated spatial prediction. Int. J. Geogr. Inform. Syst. 13, 143-158.

Tuck, G.N., Polacheck, T., Croxall, J.P., Weimerskirch, H., Prince, P.A., Wotherspoon, S., 1999. The potential of archival tags to provide long-term movement and behaviour data for seabirds: first results from Wandering Albatross Diomedea exulans of South Georgia and the Crozet Islands. EMU 99, 60-68.

Weimerskirch, H., Bonadonna, F., Bailleul, F., Mabille, G., Dell'Omo, G., Lipp, H.-P., 2002. GPS tracking of foraging albatrosses. Science 295, 1259.

Weng, K.C., Castilho, P.C., Morrissette, J.M., Landeira-Fernandez, A.M., Holts, D.B., Schallert, R.J., Goldman, K.J., Block, B.A., 2005 Satellite tagging and cardiac physiology reveal niche expansion in salmon sharks. Science 7, 104-106.

Williams, R., Hedley, S.L., Hammond, P.S., 2006. Modeling distribution and abundance of Antarctic baleen whales using ships of opportunity. Ecol. Soc. 11 (1), 1. [Online] URL: http://www.ecologyandsociety.org/vol11/iss1/art1/.

Zimmermann, F., 2004. Conservation of the Eurasian Lynx (Lynx lynx) in a fragmented landscape-habitat models, dispersal and potential distribution. Ph.D. Thesis. University of Lausanne, Lausanne, 180 pp. 